\title{
The SCFA receptor GPR43 and energy metabolism
}

\author{
Ikuo Kimura ${ }^{1,2}$ *, Daisuke Inoue ${ }^{2}$, Kanako Hirano ${ }^{2}$ and Gozoh Tsujimoto ${ }^{2}$ \\ ' Department of Applied Biological Science, Graduate School of Agriculture, Tokyo University of Agriculture and Technology, Tokyo, Japan \\ 2 Department of Pharmacogenomics, Kyoto University Graduate School of Pharmaceutical Science, Kyoto, Japan
}

\section{Edited by:}

Atsuhiko Ichimura, Tohoku University

Graduate School of Medicine, Japan

\section{Reviewed by:}

Greisa Vila, Medical University of

Vienna, Austria

Zhong Q. Wang, Pennington

Biomedical Research Center, USA

\section{*Correspondence:}

Ikuo Kimura, Department of Applied Biological Science, Graduate School of Agriculture, Tokyo University of Agriculture and Technology, 3-5-8

Saiwai-cho, Fuchu-shi, Tokyo 183-8509, Japan

e-mail: ikimura@cc.tuat.ac.jp
Free fatty acids (FFAs) are essential nutrients and act as signaling molecules in various cellular processes via binding with FFA receptors. Of these receptors, GPR43 is activated by short-chain fatty acids (SCFAs; e.g., acetate, propionate, and butyrate). During feeding, SCFAs are produced by microbial fermentation of dietary fiber in the gut, and these SCFAs become important energy sources for the host. The gut microbiota affects nutrient acquisition and energy regulation of the host and can influence the development of obesity, insulin resistance, and diabetes. Recently, GPR43 has been reported to regulate host energy homeostasis in the gastrointestinal tract and adipose tissues. Hence, GPR43 is also thought to be a potential drug target for metabolic disorders, such as obesity and diabetes. In this review, we summarize the identification, structure, and activities of GPR43, with a focus on host energy regulation, and present an essential overview of our current understanding of its physiological roles in host energy regulation that is mediated by gut microbiota. We also discuss the potential for GPR43 as a therapeutic target.

\section{INTRODUCTION}

Obesity is currently one of the most serious public health problems worldwide because of its increasing prevalence and contribution to serious metabolic disorders, including type- 2 diabetes $(1,2)$. Obesity is the result of a long-term imbalance between energy intake and expenditure, and is therefore regulated by multiple pathways involving metabolites, hormones, and neuropeptides (3). Excess food intake, especially high-fat and sugar foods, and lack of physical activity are considered as risk factors in the developing of obesity. Recent research has demonstrated that the gut microbiota is involved in obesity and metabolic disorders $(4,5)$. An important role of the gut microbiota is to catabolize substrates, such as dietary fiber, that are not completely hydrolyzed by host enzymes during host feeding (6). The main colonic bacterial fermentation products of dietary fiber are short-chain fatty acids (SCFAs), such as acetate, propionate, and butyrate (7). SCFAs can be used for de novo synthesis of lipids and glucose, which are the main energy sources for the host (8).

\section{THE SCFA RECEPTOR GPR43}

In addition to functioning as an energy source, SCFAs are also essential nutrients that act as signaling molecules. Recently, two orphan G-protein coupled receptors (GPCR), GPR41 and GPR43, were reported to be activated by SCFAs. During ligand screening for bioactive compounds, researchers reported that GPR43, also known as free fatty acid receptor 2 (FFAR2), was activated by acetate using $\mathrm{Ca}^{2+}$ assays in transfected cells $(9,10)$. GPR43 can also be activated by other SCFAs, including propionate and butyrate; acetate and propionate are the most efficient for activating GPR43, followed by butyrate and then other SCFAs $(9,11)$.

GPR43 is a dual-coupling GPCR that binds with the pertussis toxin-sensitive $\mathrm{G}_{\mathrm{i} / \mathrm{o}}$ and $\mathrm{G}_{\mathrm{q}}$ proteins (11). Stimulation of GPR43 by SCFAs inhibits cAMP production, activates the extracellular signal-regulated kinase (ERK) cascade via interactions with the $\mathrm{G}_{\mathrm{i} / \mathrm{o}}$ family of G-proteins, increases intracellular $\mathrm{Ca}^{2+}$ levels, and promotes activation of the mitogen-activated protein kinase (MAPK) cascade via interactions with the $\mathrm{G}_{\mathrm{q}}$ family of $\mathrm{G}$-proteins. However, the physiological significance of this GPR43-based dualcoupled signaling mechanism is still unclear. GPR43 is expressed in the adipose tissue, intestines, and immune tissues $(12,13)$. In the immune system, many studies have investigated the role of GPR43 in regulating inflammatory responses (13-15). These results indicate that GPR43 is important for gut immunity involving gut microbiota and food. On the other hands, GPR43 expression in adipose and gastrointestinal tissues suggests that GPR43 may be involved in energy regulation (16); moreover, reverse transcription polymerase chain reaction (RT-PCR) in mouse tissues has shown that Gpr43 is expressed in white adipose tissue (WAT) and the intestine (12).

\section{ADIPOSE TISSUES}

Adipose tissues are very important tissues associated with energy homeostasis and energy accumulation. In adipose tissues, GPR43 may be involved in regulating obesity and energy accumulation, Similarly, Gpr43 mRNA is expressed in WATs, including subcutaneous, perirenal, and epididymal tissues, as well as in 3T3-L1derived adipocytes and mature adipocytes (12). Based on the observed expression of Gpr43 in adipose tissues and adipocytes, Hong et al. performed a series of studies to elucidate the functions of GPR43 in adipocytes (12). They showed that Gpr43 expression was significantly greater in the WAT of mice with high-fat diet (HFD)-induced obesity compared with normal chow-fed mice. Moreover, in 3T3-L1 cells, treatment with SCFAs, increased Gpr43 and Pparg transcript levels, while suppression of Gpr 43 mRNA by RNA interference inhibited adipogenesis. Thus, SCFAs appear to 
promote adipogenesis via GPR43. Additionally, in 3T3-L1 derived adipocytes, SCFAs suppress isoproterenol-induced lipolysis in a concentration-dependent manner (12). Ge et al. demonstrated that these effects are dependent on GPR43 using Gpr43-deficient mice (17). That is, they showed that acetate suppressed lipolysis, and release of glycerol occurred in a concentration-dependent manner in adipocytes isolated from wild-type mice in vitro, and the activation of GPR43 by intraperitoneal injection of sodium acetate instantly reduced plasma fatty acid in vivo; these effects were abrogated in Gpr43-knockout mice (17). In brown adipose tissues (BATs), which have a central role in the regulation of energy balance and homeostasis, Bjursell et al. reported that Gpr43-knockout mice fed an HFD exhibited improved insulin sensitivity in old age due to increased energy expenditure, which resulted in increased body temperature (18). As a potential explanation for this, histological observation of BAT in Gpr43-knockout mice revealed that these mice exhibited decreased lipid dispersion compared with wild-type mice fed an HFD. However, we could not detect Gpr43 expression in BATs (19). Hence, further studies are needed to elucidate the role of GPR43 in energy control via BAT.

Recent evidence suggests that the gut microbiota affects host nutrient acquisition and energy regulation and is therefore related to obesity, insulin resistance, and diabetes in the host (20-22). During feeding, SCFAs, which act as ligands for GPR43, are produced by microbial fermentation of dietary fiber in the gut. Hence, we examined the relationship between gut microbiota and systemic energy regulation by GPR43 in adipose tissue using Gpr43-mutantand germ-free mice (19). In a series of in vitro and in vivo studies, we found that Gpr43 deficiency induced obesity in mice, while mice that overexpress Gpr43 only in adipose tissues were lean under normal conditions; both of these mouse strains did not exhibit either phenotype under germ-free conditions or after antibiotic treatment. Furthermore, SCFAmediated GPR43 activation suppressed adipose insulin signaling, leading to inhibition of fat accumulation in the adipose tissue, and unincorporated lipids and glucose were primarily utilized in muscles. That is, the expression of energy expenditure-, glycolysis-, and beta-oxidation-related genes increased, while the expression of gluconeogenesis-related genes decreased in the muscles of aP2-Gpr43 TG mice. However, the mechanism by which GPR43 mediated the suppression of insulin signaling in adipocytes is not mediated by cAMP inhibition, but instead involves the beta and gamma subunits of the $\mathrm{G}_{\mathrm{i} / \mathrm{o}}$ protein, not $\mathrm{G}_{\mathrm{q}}$ protein. Thus, GPR43 acts as a sensor for excessive dietary energy, thereby controlling body energy utilization while maintaining metabolic homeostasis. The GPR43-insulin pathway in adipose tissue may function as an important physiological mechanism through which these metabolic fuels regulate body energy balance. Hence, these previous reports in adipose tissues indicate that GPR43 has potential therapeutic relevance for the treatment of metabolic disorders, such as obesity and type- 2 diabetes.

\section{INTESTINAL TISSUES}

In the intestines, GPR43 may be involved in regulating appetite and insulin signaling. Indeed, Gpr43 mRNA has been shown to be expressed in rat and human ileum and colon, especially in

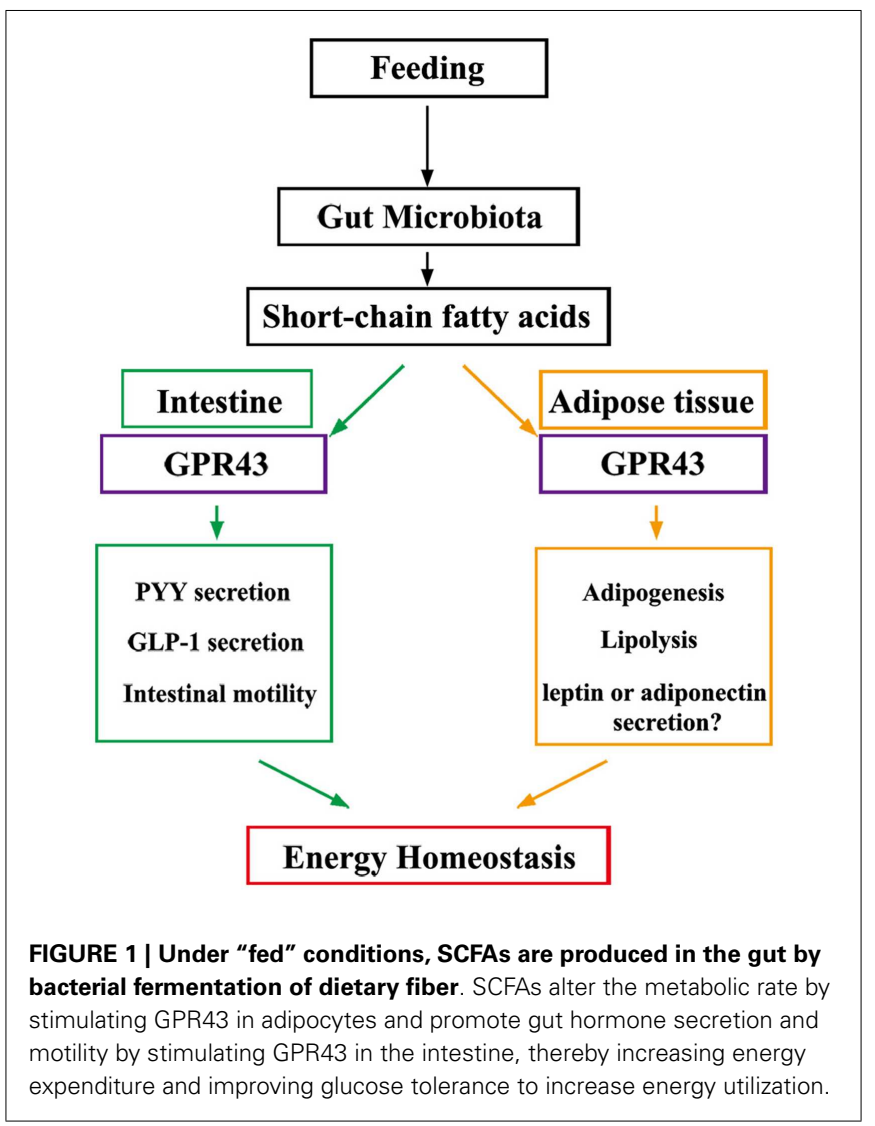

enteroendocrine cells $(23,24)$. Like adipose tissue, the intestine is also critical for energy homeostasis, as supported by its association with secretion of appetite gut hormones and nutrients absorption $(25,26)$. Using immunohistochemistry analysis with GPR43 antibodies in rats, Karaki et al. reported that GPR43 is expressed in peptide YY (PYY)-containing enteroendocrine L-cells of the gastrointestinal tract (23). Enteroendocrine L-cells are also one of the major cell types that express the proglucagon genes GLP-1 and GLP-2. GLP-1 and GLP-2 proteins are co-stored and cosecreted with PYY from enteroendocrine L-cells (27), and SCFAs are co-secreted with GLP-1 from mixed colonic cultures via GPR43 in vitro and in vivo (28). Quantitative RT-PCR (qRT-PCR) showed that Gpr43 and Gpr41 were abundantly expressed in GLP-1secreting L-cells. Moreover, SCFAs raised cytosolic $\mathrm{Ca}^{2+}$ through $\mathrm{G}_{\mathrm{q}}$ signaling pathways in L-cells in primary culture. Gpr43- or Gpr41-knockout mice exhibited reduced SCFA-mediated GLP-1 secretion both in vitro and in vivo and have impaired glucose tolerance. Additionally, Gpr43-knockout mice exhibited reduction of insulin secretion in accompaniment with the reduction of in vivo glucose-stimulated GLP-1 secretion (28). However, to determine the effects of SCFAs on the secretion of gut hormones, the expression and function of GPR41, and GPR43 in subtypes of enteroendocrine cells, such as L-cells and K-cells, must be characterized in detail using Gpr41- and Gpr43-double-knockout mice. Thus, pharmacological manipulation of appetite using a GPR43 agonist may be useful for treatment of obesity. Moreover, these types of studies may provide essential information concerning 
the role of GLP-1 in insulin secretion in patients with type-2 diabetes. The anorexigenic neural circuits are subsequently activated via PYY and GLP-1, reducing food intake and increasing energy expenditure. Hence, regulation of PYY and GLP-1 secretion via GPR43 maintains energy homeostasis and may be a valid approach for treating metabolic disorders.

\section{CONCLUSION}

GPR43 regulates metabolic rate when activated by SCFAs that are produced by gut microbiota in a variety of host tissues (Figure 1). Future studies are expected to reveal the presence of a central mechanism that mediates the effects of diet and probiotics on human homeostasis. Additionally, GPR43 may represent a promising therapeutic target for the treatment of metabolic syndromes, such as obesity and diabetes.

\section{REFERENCES}

1. Kahn SE, Hull RL, Utzschneider KM. Mechanisms linking obesity to insulin resistance and type 2 diabetes. Nature (2006) 444:840-6. doi:10.1038/ nature 05482

2. Sanz Y, Santacruz A, Gauffin P. Gut microbiota in obesity and metabolic disorders. Proc Nutr Soc (2010) 69:434-41. doi:10.1017/S0029665110001813

3. Greenwood HC, Bloom SR, Murphy KG. Peptides and their potential role in the treatment of diabetes and obesity. Rev Diabet Stud (2011) 8:355-68. doi:10.1900/RDS.2011.8.355

4. Greiner T, Backhed F. Effects of the gut microbiota on obesity and glucose homeostasis. Trends Endocrinol Metab (2011) 22:117-23. doi:10.1016/j.tem. 2011.01.002

5. Kau AL, Ahern PP, Griffin NW, Goodman AL, Gordon JI. Human nutrition, the gut microbiome and the immune system. Nature (2011) 474:327-36. doi:10.1038/nature 10213

6. Topping DL, Clifton PM. Short-chain fatty acids and human colonic function: roles of resistant starch and nonstarch polysaccharides. Physiol Rev (2001) 81:1031-64.

7. Flint HJ, Bayer EA, Rincon MT, Lamed R, White BA. Polysaccharide utilization by gut bacteria: potential for new insights from genomic analysis. Nat Rev Microbiol (2008) 6:121-31. doi:10.1038/nrmicro1817

8. Wolever TM, Brighenti F, Royall D, Jenkins AL, Jenkins DJ. Effect of rectal infusion of short chain fatty acids in human subjects. Am J Gastroenterol (1989) 84:1027-33.

9. Brown AJ, Goldsworthy SM, Barnes AA, Eilert MM, Tcheang L, Daniels D, et al. The orphan G protein-coupled receptors GPR41 and GPR43 are activated by propionate and other short chain carboxylic acids. J Biol Chem (2003) 278:11312-9. doi:10.1074/jbc.M211609200

10. Nilsson NE, Kotarsky K, Owman C, Olde B. Identification of a free fatty acid receptor, FFA2R, expressed on leukocytes and activated by short-chain fatty acids. Biochem Biophys Res Commun (2003) 303:1047-52. doi:10.1016/S0006291X(03)00488-1

11. Le Poul E, Loison C, Struyf S, Springael JY, Lannoy V, Decobecq ME, et al. Functional characterization of human receptors for short chain fatty acids and their role in polymorphonuclear cell activation. J Biol Chem (2003) 278:25481-9. doi:10.1074/jbc.M301403200

12. Hong YH, Nishimura Y, Hishikawa D, Tsuzuki H, Miyahara H, Gotoh C, et al. Acetate and propionate short chain fatty acids stimulate adipogenesis via GPCR43. Endocrinology (2005) 146:5092-9. doi:10.1210/en.2005-0545

13. Maslowski KM, Vieira AT, Ng A, Kranich J, Sierro F, Yu D, et al. Regulation of inflammatory responses by gut microbiota and chemoattractant receptor GPR43. Nature (2009) 461:1282-6. doi:10.1038/nature08530

14. Sina C, Gavrilova O, Forster M, Till A, Derer S, Hildebrand F, et al. G proteincoupled receptor 43 is essential for neutrophil recruitment during intestinal inflammation. J Immunol (2009) 183:7514-22. doi:10.4049/jimmunol.0900063
15. Smith PM, Howitt MR, Panikov N, Michaud M, Gallini CA, Bohlooly YM, et al. The microbial metabolites, short-chain fatty acids, regulate colonic Treg cell homeostasis. Science (2013) 341:569-73. doi:10.1126/science.1241165

16. Sleeth ML, Thompson EL, Ford HE, Zac-Varghese SE, Frost G. Free fatty acid receptor 2 and nutrient sensing: a proposed role for fibre, fermentable carbohydrates and short-chain fatty acids in appetite regulation. Nutr Res Rev (2010) 23:135-45. doi:10.1017/S0954422410000089

17. Ge H, Li X, Weiszmann J, Wang P, Baribault H, Chen JL, et al. Activation of GPR43 in adipocytes leads to inhibition of lipolysis and suppression of plasma free fatty acids. Endocrinology (2008) 149:4519-26. doi:10.1210/en.2008-0059

18. Bjursell M, Admyre T, Goransson M, Marley AE, Smith DM, Oscarsson J, et al. Improved glucose control and reduced body fat mass in free fatty acid receptor 2-deficient mice fed a high-fat diet. Am J Physiol Endocrinol Metab (2011) 300:E211-20. doi:10.1152/ajpendo.00229.2010

19. Kimura I, Ozawa K, Inoue D, Imamura T, Kimura K, Maeda T, et al. The gut microbiota suppresses insulin-mediated fat accumulation via the shortchain fatty acid receptor GPR43. Nat Commun (2013) 4:1829. doi:10.1038/ ncomms 2852

20. Turnbaugh PJ, Ley RE, Mahowald MA, Magrini V, Mardis ER, Gordon JI. An obesity-associated gut microbiome with increased capacity for energy harvest. Nature (2006) 444:1027-31. doi:10.1038/nature05414

21. Turnbaugh PJ, Hamady M, Yatsunenko T, Cantarel BL, Duncan A, Ley RE, et al. A core gut microbiome in obese and lean twins. Nature (2009) 457:480-4. doi:10.1038/nature07540

22. Delzenne NM, Neyrinck AM, Backhed F, Cani PD. Targeting gut microbiota in obesity: effects of prebiotics and probiotics. Nat Rev Endocrinol (2011) 7:639-46. doi:10.1038/nrendo.2011.126

23. Karaki S, Mitsui R, Hayashi H, Kato I, Sugiya H, Iwanaga T, et al. Short-chain fatty acid receptor, GPR43, is expressed by enteroendocrine cells and mucosal mast cells in rat intestine. Cell Tissue Res (2006) 324:353-60. doi:10.1007/s00441005-0140- $\mathrm{x}$

24. Karaki S, Tazoe H, Hayashi H, Kashiwabara H, Tooyama K, Suzuki Y, et al. Expression of the short-chain fatty acid receptor, GPR43, in the human colon. J Mol Histol (2008) 39:135-42. doi:10.1007/s10735-007-9145-y

25. Turton MD, O'Shea D, Gunn I, Beak SA, Edwards CM, Meeran K, et al. A role for glucagon-like peptide-1 in the central regulation of feeding. Nature (1996) 379:69-72. doi:10.1038/379069a0

26. Batterham RL, Cowley MA, Small CJ, Herzoq H, Cohen MA, Dakin CL, et al. Gut hormone PYY(3-36) physiologically inhibits food intake. Nature (2002) 418:650-4. doi:10.1038/nature00887

27. Kim BJ, Carlson OD, Jang HJ, Elahi D, Berry C, Egan JM. Peptide YY is secreted after oral glucose administration in a gender-specific manner. J Clin Endocrinol Metab (2005) 90:6665-71. doi:10.1210/jc.2005-0409

28. Tolhurst G, Heffron H, Lam YS, Parker HE, Habib AM, Diakogiannaki E, et al. Short-chain fatty acids stimulate glucagon-like peptide-1 secretion via the Gprotein-coupled receptor FFAR2. Diabetes (2012) 61:364-71. doi:10.2337/db111019

Conflict of Interest Statement: The authors declare that the research was conducted in the absence of any commercial or financial relationships that could be construed as a potential conflict of interest.

Received: 05 April 2014; accepted: 23 May 2014; published online: 05 June 2014. Citation: Kimura I, Inoue D, Hirano $K$ and Tsujimoto $G$ (2014) The SCFA receptor GPR43 and energy metabolism. Front. Endocrinol. 5:85. doi: 10.3389/fendo.2014.00085

This article was submitted to Diabetes, a section of the journal Frontiers in Endocrinology.

Copyright (c) 2014 Kimura, Inoue, Hirano and Tsujimoto. This is an open-access article distributed under the terms of the Creative Commons Attribution License (CC $B Y)$. The use, distribution or reproduction in other forums is permitted, provided the original author(s) or licensor are credited and that the original publication in this journal is cited, in accordance with accepted academic practice. No use, distribution or reproduction is permitted which does not comply with these terms. 